\title{
PRODUÇÃO DE SEIS HÍBRIDOS DE SORGO COM CAPIM-SUDÃO AVALIADOS EM TRÊS CORTES E EM DUAS ÉPOCAS DE SEMEADURA
}

\author{
ALEXANDRE GUALBERTO PENNA ${ }^{1}$, ANA LUIZA COSTA CRUZ BORGES², LÚCIO \\ CARLOS GONÇALVES ${ }^{2}$, JOSÉ AVELINO SANTOS RODRIGUES ${ }^{3}$, SILAS PRIMOLA \\ GOMES ${ }^{4}$, CLÁUDIA FREIRE ANDRADE MORAIS PENNA², IRAN BORGES²; \\ NORBERTO MÁRIO RODRIGUEZ ${ }^{2}$ e RICARDO REIS E SILVA ${ }^{4}$
}

\author{
${ }^{1}$ Mestre em Zootecnia pela Escola de Veterinária da UFMG, Caixa postal 567, CEP: 30123- \\ 970- Belo Horizonte/MG \\ ${ }^{2}$ Professor(a) da Escola de Veterinária da UFMG, Caixa postal 567, CEP: 30123-970- Belo \\ Horizonte/MG; analuiza@vet.ufmg.br \\ ${ }^{3}$ Pesquisador do CNPMS/EMBRAPA, Sete Lagoas/MG \\ ${ }^{4}$ Doutorando em Zootecnia pela Escola de Veterinária da UFMG; ricreis1@hotmail.com
}

Revista Brasileira de Milho e Sorgo, v.9, n.1, p. 93-105, 2010

RESUMO - Foram avaliados quatro híbridos experimentais e duas cultivares comerciais de Sorghum bicolor cv bicolor X Sorghum bicolor cv sudanense quanto à produção de matéria verde (MV), matéria seca (MS) e matéria seca digestível (MSD), altura das plantas e população por hectare. Os híbridos foram semeados em duas épocas e submetidos a três cortes sucessivos. Foi empregado o delineamento experimental de blocos ao acaso, com parcelas subdivididas, e a comparação de médias foi efetuada pelo teste de SNK, a 5\% de probabilidade. O híbrido ATF 53 x CMSXS 912 apresentou valores médios de produção de MV, MS e MSD superiores aos demais, nas duas épocas de semeadura, sem diferir da testemunha AG2501-C. Os valores médios da $2^{\mathrm{a}}$ época foram superiores aos da $1^{\mathrm{a}}$ época quanto às produções de MV, MS e altura das plantas.

Palavras-chave: características agronômicas, forragem, pastejo, digestibilidade, sorghum bicolor. 


\title{
PRODUCTION OF SIX SORGHUM-SUDANGRASS HYBRIDS SUBMITTED TO THREE CUTS AND TWO PLANTING SEASONS
}

\begin{abstract}
Four experimental hybrids and two commercial hybrids of Sorghum bicolor cv bicolor X Sorghum bicolor cv sudanense were evaluated regarding their agronomical characteristics: green matter GM), dry matter (DM), digestible dry matter (DDM) production, plant height and number of plants per hectare. The hybrids were submitted to three successive cuts, accomplished at two different planting times. A randomized blocks design was used and means were compared using SNK test $(\mathrm{p}<0.05)$. The ATF53 x CMSXS 912 showed higher average values of GM, DM and DDM productions than other hybrids at the two planting seasons, but did not differ from control AG2501-C. Average values in the second planting time were higher than in the first regarding GM and DM production and plant height, pointing to a tendency of higher production at the second time.
\end{abstract}

Key words: agronomic characteristics, forage, grazing, digestibility, sorghum bicolor.

No setor agropecuário, os baixos custos de produção, a produtividade e a qualidade são requisitos básicos para o sucesso econômico da atividade. Ao produtor, impõe-se a racionalização de seus custos, com a maximização da utilização de seu capital. Um dos principais itens no custo da produção da agropecuária brasileira refere-se aos gastos com alimentação animal. No caso do gado leiteiro, mais de $50 \%$ dos custos diários com os animais podem ser decorrentes de sua alimentação. Outro fato que ocorre é a elevação dos custos de produção na época da seca, devido à escassez de alimentos e de pastagens na entressafra.

Nas condições do Brasil Central, no período do final do inverno e início da primavera, ocorrem baixas disponibilidade e qualidade do volumoso, sendo estas as principais limitações para a máxima produção de animais em pastagens tropicais (Euclides, 2002). A utilização de uma gramínea anual mais tolerante à seca, cultivada nesse período, contribui para suprir a necessidade de um volumoso de boa qualidade.

O capim-sudão e seus híbridos com o sorgo vêm ganhando importância crescente na alimentação de rebanhos de corte e de leite, por sua facilidade de cultivo, rapidez no estabelecimento e crescimento e, principalmente, pela facilidade de manejo para corte e/ou pastejo, além de bom valor nutritivo e da alta produção de forragem (Zago, 1997). O sorgo forrageiro para corte e/ou pastejo é proveniente de cruzamentos de espécies do gênero Sorghum. Usa-se como 
macho uma linhagem de capim-sudão (Sorghum bicolor cv sudanense) e, como fêmea, uma linhagem de sorgo granífero (Sorghum bicolor cv bicolor) (Raupp et al., 1999).

Deve-se ressaltar também que as áreas destinadas à produção de silagem no Brasil Central são colhidas na época das chuvas, causando compactação do solo, ficando paralisadas na maioria das vezes, durante o outono-inverno. Com a ausência de resíduos e culturas de rotação nessas áreas, o solo fica com baixo teor de matéria orgânica e demasiadamente compactado, prejudicando o preparo e o estabelecimento da cultura subseqüente, com resultados negativos na produtividade final. A adoção de tecnologias como a dos híbridos de sorgo com capim-sudão, que rebrotam após os cortes, pode ajudar a minimizar os efeitos negativos sobre o solo dessas áreas de cultivo. Contudo, informações sobre os parâmetros produtivos de híbridos de sorgo com capimsudão submetidos a diferentes condições de manejo são raras.

Este estudo teve como objetivo avaliar o potencial forrageiro de seis híbridos de sorgo (Sorghum bicolor cv bicolor) com capim-sudão (Sorghum bicolor cv sudanense), semeados em duas épocas e submetidos a três cortes.

\section{Material e Métodos}

O experimento foi instalado no município de Sete Lagoas - MG, em área da Embrapa Milho e Sorgo, com as seguintes coordenadas geográficas: $19^{\circ}$ de latitude sul e $44^{\circ}$ de longitude oeste de Greenwich, com altitude média de $732 \mathrm{~m}$ e precipitação pluviométrica média de $1.340 \mathrm{~mm}$, da qual 86,2\% ocorrem no período de novembro a abril. O clima da região é do tipo AW (classificação de Köppen), clima de savana, com inverno seco e temperatura média no mês mais frio acima de $18^{\circ} \mathrm{C}$.

Foram cultivados seis híbridos, dos quais dois eram cultivares comerciais, híbridos do sorgo com capim-sudão, AG 2501-C e BRS 800, usados como testemunhas, e quatro eram genótipos experimentais, CMSXS 205 x CMSXS 912, CMSXS 206 x CMSXS 912, CMSXS 222 x CMSXS 912 e ATF53 x CMSXS 912, desenvolvidos pela Embrapa Milho e Sorgo. A identificação dos híbridos CMSXS será feita apenas pelos números correspondentes. $\mathrm{O}$ delineamento experimental empregado foi o de blocos ao acaso, com parcelas subdivididas, com quatro repetições, utilizando seis híbridos, três cortes sucessivos e duas épocas de semeadura. Os dados foram avaliados por meio de análise de variância e teste de média, utilizando-se o Sistema de Análises Estatísticas e Genéticas - SAEG (UFV, 2000). Para a comparação das médias, foi empregado o teste SNK (Student Newman Keuls), a 5\% de probabilidade.

Cada parcela experimental continha quatro linhas de $5 \mathrm{~m}$ de comprimento, espaçadas $0,35 \mathrm{~m}$ entre si, totalizando $7 \mathrm{~m}^{2}$. Foram realizadas as adubações de semeadura, utilizando-se $300 \mathrm{kgha}^{-1}$ da formulação 04-14-08 (N: P: K), e de cobertura, $100 \mathrm{~kg} \mathrm{ha}^{-1}$ de uréia. Quando necessário, durante 
todo o período, foram realizadas irrigações por aspersão. As temperaturas médias observadas no local, nos últimos três anos, para os meses de outubro, novembro, dezembro e janeiro, foram, respectivamente, de 22,$1 ; 22,1 ; 22,3$ e $22,9{ }^{\circ} \mathrm{C}$ e as precipitações médias nesse mesmo período e nos meses analisados foram, respectivamente 115,$7 ; 217,2 ; 266,3$ e $289 \mathrm{~mm}$.

A primeira semeadura foi realizada no dia 22 de agosto de 2001. Os cortes foram realizados aos 50 dias após a semeadura (DAS), aos 26 dias após o primeiro corte e aos 27 após a segundo corte.

A segunda semeadura foi realizada no dia 4 de setembro de 2001, ou seja, 13 dias após a primeira. Os cortes foram realizados aos 48 DAS, aos 32 dias após o primeiro corte e aos 41 dias após o segundo corte.

Devido às condições ambientais desfavoráveis durante a realização do experimento, excesso de chuvas, não foi possível a padronização dos intervalos dos cortes nas diferentes épocas, o que impediu a realização de colheitas, adubações e tratos culturais exatamente no momento planejado.

Antes de cada corte, foram realizadas a contagem das plantas e a medição da altura de planta, considerando a distância do nível do solo ao horizonte visual das folhas superiores. Em seguida, todo o material presente no canteiro foi colhido, sendo o corte realizado na altura de $20 \mathrm{~cm}$ acima do solo, semelhante às condições de pastejo. Após o corte, o material colhido foi pesado em dinamômetro, para se obterem as produções de matéria verde (MV) e matéria seca (MS), em kg.ha-1.

Após a moagem do material em picadeira estacionária e homogeneização, foram retiradas as amostras, as quais foram encaminhadas ao Laboratório de Nutrição da Escola de Veterinária da UFMG. O material foi pesado e secado em estufa de ventilação forçada a $65^{\circ} \mathrm{C}$, por 72 horas, e posteriormente moído em moinho com peneira de $1 \mathrm{~mm}$, para realização das análises bromatológicas. As amostras pré-secadas foram utilizadas para a determinação dos teores de MS a $105^{\circ} \mathrm{C}$ e de cinzas (Cunnif, 1995), da digestibilidade in vitro da MS (DIVMS), de acordo com o método de Tilley \& Terry (1963). As produções de matéria seca digestível (MSD), por sua vez, foram obtidas multiplicando-se a produção de MS de cada canteiro pela sua DIVMS.

\section{Resultados e Discussão}

A determinação da produção $\mathrm{MV}$ é um parâmetro que se justifica pela sua facilidade de mensuração e de utilização no campo. Os dados de produção de MV da primeira e da segunda épocas de semeadura e da produção total obtidos no presente estudo estão contidos na Tabela 1 . O genótipo experimental ATF 53 x 912 apresentou produção média de matéria verde semelhante $(\mathrm{p}>0,05)$ à da cultivar AG 2501-C e superior $(\mathrm{p}<$ $0,05)$ à dos demais híbridos do experimento.

Comparando-se os híbridos na primeira época, não foi encontrada diferença do 
TABELA 1. Produção de matéria verde $\left(\mathrm{t} \mathrm{ha}^{-1}\right)^{1}$ da planta de híbridos de sorgo, em diferentes épocas de semeadura e corte.

\begin{tabular}{|c|c|c|c|c|c|c|c|c|c|}
\hline \multirow[b]{2}{*}{ Híbridos } & \multicolumn{4}{|c|}{$1^{\text {a Época }}$} & \multicolumn{4}{|c|}{$2^{\mathrm{a}}$ Época } & \multirow[b]{2}{*}{ Média } \\
\hline & $1^{\circ}$ Corte & $2^{\circ}$ Corte & $3^{\circ}$ Corte & $\begin{array}{c}\text { Produção } \\
\text { Total }\end{array}$ & $1^{\circ}$ Corte & $2^{\circ}$ Corte & $3^{\circ}$ Corte & $\begin{array}{c}\text { Produção } \\
\text { Total }\end{array}$ & \\
\hline $206 \times 912$ & $10,48 \mathrm{Aa}$ & 5,06 Aa & $6,13 \mathrm{Ba}$ & $21,66 \mathrm{Aa}$ * & 6,56 Ab’ & $20,09 \mathrm{Ba}^{\prime}$ & $5,55 \mathrm{Bb}$ & $32,21 \mathrm{Ca} *$ & $8,98 \mathrm{C}$ \\
\hline $205 \times 912$ & $13,82 \mathrm{Aa}$ & 9,41 Aa & $9,91 \mathrm{Ba}$ & 33,13Aa* & 8,27 Ab' & $27,29 \mathrm{Ba}^{\prime}$ & $11,83 \mathrm{ABb}$ & 47,38Вса* & $13,42 \mathrm{BC}$ \\
\hline ATF $53 \times 912$ & $15,96 \mathrm{Aab}$ & $8,41 \mathrm{Ab}$ & $22,16 \mathrm{Aa}$ & $46,53 \mathrm{Ab}$ & $12,26 \mathrm{Ac}$ & $38,90 \mathrm{Aa}^{\prime}$ & $22,37 \mathrm{Ab}$ & 73,53Aa* & $20,01 \mathrm{~A}$ \\
\hline $222 \times 912$ & $10,98 \mathrm{Aa}$ & $8,27 \mathrm{Aa}$ & $6,63 \mathrm{Ba}$ & $25,80 \mathrm{Aa}^{*}$ & 9,12 Ab' & $24,80 \mathrm{Ba}^{\prime}$ & $8,84 \mathrm{Bb}$ & $42,75 \mathrm{Bca}^{*}$ & $11,14 \mathrm{C}$ \\
\hline AG 2501-C & $14,97 \mathrm{Aa}$ & $10,40 \mathrm{Aa}$ & $17,67 \mathrm{ABa}$ & $43,04 \mathrm{Aa}^{*}$ & $11,12 \mathrm{Ab}$ & $30,78 \mathrm{ABa}^{\prime}$ & $17,10 \mathrm{ABb}$ & $59,00 \mathrm{Aba}^{*}$ & $17,01 \mathrm{AB}$ \\
\hline BRS 800 & $13,76 \mathrm{Aa}$ & $9,55 \mathrm{Aa}$ & $13,11 \mathrm{ABa}$ & 36,41 Aa* & $10,26 \mathrm{Aa}^{\prime}$ & $19,95 \mathrm{Ba}^{\prime}$ & $14,5 \mathrm{ABa}$ & 47,76Bca * & $13,52 \mathrm{BC}$ \\
\hline Médias & 13,33 & 8,52 & 12,60 & $34,43 b^{*}$ & 9,60 & 26,97 & 13,37 & 49,94a* & \\
\hline
\end{tabular}

${ }^{1}$ Médias seguidas de letras maiúsculas iguais na mesma coluna, de letras minúsculas iguais na mesma linha, letras minúsculas iguais com apóstrofe na mesma linha e letras minúsculas iguais com asterisco na mesma linha não diferem pelo teste $\mathrm{SNK}(\mathrm{p}<0,05)$. CV = 44,02\% (produção parcial); $\mathrm{CV}=29,26 \%$ (produção total)

rendimento obtido no primeiro e no segundo cortes. Entretanto, no terceiro corte, o genótipo ATF 53 x 912 produziu valor semelhante ao obtido com as testemunhas AG 22501-C e BRS 800 e superior aos outros genótipos. Entre os demais híbridos, não foram encontradas diferenças. Observou-se diferença entre os cortes apenas para o genótipo ATF 53 x 912, principalmente devido à maior produção no terceiro corte.

Em relação à segunda época, a produção média de MV.ha-1 foi semelhante entre os híbridos no primeiro corte. Já para o segundo corte, o rendimento apresentado pelo genótipo ATF 53 x 912 foi semelhante apenas ao da cultivar AG 2501-C, sendo superior ao dos outros híbridos. No terceiro corte, foi observado que o mesmo genótipo ATF 53 x 912 proporcionou produções de forragem superiores à dos aos genótipos 206 x 912 e 222 x 912 e semelhantes à dos demais híbridos, entre os quais não foram detectadas diferenças. Na segunda época, apenas o híbrido BRS 800 apresentou estabilidade de produção de $\mathrm{MV} /$ ha ao longo dos cortes, enquanto os demais híbridos apresentaram produções no segundo corte superiores às dos demais cortes.

$\mathrm{Na}$ primeira época de semeadura, a produção média de MV por corte foi de 11,48 $\mathrm{t}$, sendo inferior à produção média obtida na segunda época. Essa diferença pode ser explicada parcialmente pelo maior tempo de cultivo apresentado na segunda época, de 121 dias, em relação aos 109 dias da primeira época, o que contribuiu, juntamente com os fatores climáticos, para diferentes taxas de crescimento.

Esses valores estão de acordo com as produções médias de 40 a 60 t.ha ${ }^{-1}$ relatadas por Zago (1997), para os híbridos de sorgo 
com capim-sudão, obtidas em três cortes consecutivos, e por Ribas et al. (2002) de 43,3 a 61,3 t.ha $^{-1}$, para doze híbridos colhidos aos 55 dias após a semeadura e com 29 e 30 dias de rebrota, e superiores aos obtidos por Tomich (2003), de 50,3 a 85,7 t.ha-1, para 12 híbridos, em três cortes sucessivos, principalmente por apresentarem produções mais constantes entre os cortes.

Apesar disso, as produções alcançadas no atual trabalho podem ser consideradas satisfatórias, levando-se em consideração que a semeadura em agosto e setembro propiciou a obtenção de forragem no período em que as pastagens no Brasil Central ainda estão se recuperando do período de estiagem.

Os valores de produção de MV variaram de 5,06 a 38,90 t.ha ${ }^{-1}$ e foram positivamente correlacionados $(p<0,001)$ com a altura das plantas. Ainda que tenham sido pretendidas colheitas em estádios semelhantes nas diferentes épocas e cortes sucessivos, a interferência de fatores ambientais relatada anteriormente levou à realização de cortes em intervalos desiguais de dias, o que possibilitou distintos crescimentos das plantas, levando às diferenças de produção observadas entre as épocas e entre os cortes.

O genótipo ATF 53 x 912 apresentou produção de 38,90 t.ha-1 na segunda época, com apenas 32 dias de rebrota, demonstrando todo seu potencial de produção e a excelente capacidade de crescimento dos híbridos de sorgo com capim-sudão. De forma semelhante,
Borges et al. (2003), trabalhando com híbridos de sorgo, obtiveram produções superiores para a segunda (17,84 t.ha-1 $\left.{ }^{-1}\right)$ época de semeadura, em relação à primeira $\left(12,79\right.$ t.ha $\left.{ }^{-1}\right)$.

Os valores médios observados nas duas épocas, para o genótipo ATF 53 x $912(60,03$ t.ha $\left.\mathrm{a}^{-1}\right)$, foram semelhantes $(\mathrm{p}<0,05)$ aos da cultivar AG 2501-C (51,01 t.ha-1) e superiores $(p<0,05)$ aos das demais. As médias de produção acumulada de MV variaram de 26,93 a 40,58 t.ha-1 para os outros híbridos e não apresentaram diferenças $(\mathrm{p}>0,05)$. Ao analisar cada época isoladamente, houve diferenças ( $p>0,05)$ entre os híbridos. Apenas na segunda época, a produção acumulada do genótipo ATF 53 x 912 foi semelhante ao valor obtido pela cultivar AG 2501-C e superior às demais produções obtidas pelos híbridos restantes.

As produções de MS são apresentadas na Tabela 2. Observou-se uma correlação de 0,98 $(\mathrm{p}<0,001)$ dessa característica com a produção de MV. Comparando os resultados presentes nas Tabelas 1 e 2, verifica-se que o teor médio de MS do material colhido durante todo o ensaio foi baixo, próximo de 13,5\%.

$\mathrm{Na}$ segunda época de semeadura, os híbridos não diferiram entre si $(\mathrm{p}<0,05)$ no primeiro corte. Contudo, no segundo corte, o genótipo ATF 53 x 912 apresentou rendimento semelhante $(p>0,05)$ ao dos híbridos AG 2501C e 205 x 912, e superior $(p<0,05)$ ao dos demais híbridos, que não apresentaram diferenças entre si. No terceiro corte, a produção de MS dos híbridos foi semelhante ao corte anterior, 
TABELA 2. Produção de matéria seca $\left(\mathrm{t} \mathrm{ha}^{-1}\right)^{1}$ da planta de híbridos de sorgo, em diferentes épocas de semeadura e corte.

\begin{tabular}{|c|c|c|c|c|c|c|c|c|c|}
\hline \multirow[b]{2}{*}{ Híbridos } & \multicolumn{4}{|c|}{$1^{\text {a Época }}$} & \multicolumn{4}{|c|}{$2^{\text {a Época }}$} & \multirow[b]{2}{*}{ Média } \\
\hline & $1^{\circ}$ Corte & $2^{\circ}$ Corte & $3^{\circ}$ Corte & $\begin{array}{c}\text { Produção } \\
\text { Total }\end{array}$ & $1^{\circ}$ Corte & $2^{\circ}$ Corte & $3^{\circ}$ Corte & $\begin{array}{c}\text { Produção } \\
\text { Total }\end{array}$ & \\
\hline $206 \times 912$ & 1,34 Aa & $0,85 \mathrm{Aa}$ & $0,93 \mathrm{Ca}$ & 3,12 $\mathrm{Aa}^{*}$ & $0,85 \mathrm{Ab}$ & $2,83 \mathrm{Ba}$ & 0,76 Bb' & 4,43 $\mathrm{Ba} *$ & $1,26 \mathrm{C}$ \\
\hline $205 \times 912$ & 1,54 Aa & $1,29 \mathrm{Aa}$ & $1,41 \mathrm{Bca}$ & 4,23 $\mathrm{Aa}^{*}$ & $0,95 \mathrm{Ab}$ & $3,67 \mathrm{ABa}^{\prime}$ & $1,65 \mathrm{ABb}$ & $6,26 \mathrm{Ba}^{*}$ & $1,75 \mathrm{BC}$ \\
\hline ATF53x912 & $1,82 \mathrm{Ab}$ & $1,28 \mathrm{Ab}$ & $3,45 \mathrm{Aa}$ & $6,55 \mathrm{Ab}^{*}$ & $1,47 \mathrm{Ac}$ & 4,99 Aa' & $2,87 \mathrm{Ab}$ & 9,33 $\mathrm{Aa}^{*}$ & $2,65 \mathrm{~A}$ \\
\hline $222 \times 912$ & 1,32 Aa & $1.19 \mathrm{Aa}$ & 0,99 Ca & 3,50 $\mathrm{Aa}^{*}$ & $1,07 \mathrm{Ab}$ & 3,20 Ba' & 1,20 Bb’ & $5,47 \mathrm{Ba}^{*}$ & $1,49 \mathrm{C}$ \\
\hline AG 2501-C & 1,69 Aa & $1,54 \mathrm{Aa}$ & 2,74 Aba & 5,96 $\mathrm{Aa}^{*}$ & $1,30 \mathrm{Ab}$ & 3,96 Aba' & $2,31 \mathrm{ABb}$ & 7,58 $\mathrm{Aba}^{*}$ & $2,25 \mathrm{AB}$ \\
\hline BRS 800 & $1,71 \mathrm{Aa}$ & $1,45 \mathrm{Aa}$ & $2,01 \mathrm{Bca}$ & 5,17 $\mathrm{Aa}^{*}$ & $1,35 \mathrm{Aa}^{\prime}$ & 2,64 Ba' & $1,86 \mathrm{ABa}^{\text {' }}$ & $5,84 \mathrm{Ba}^{*}$ & $1,84 \mathrm{BC}$ \\
\hline Médias & 1,57 & 1,27 & 1,92 & $4,75 b^{*}$ & 1,17 & 3,55 & 1,78 & $6,49 a^{*}$ & \\
\hline
\end{tabular}

${ }^{1}$ Médias seguidas de letras maiúsculas iguais na mesma coluna, de letras minúsculas iguais na mesma linha, letras minúsculas iguais com apóstrofe na mesma linha e letras minúsculas iguais com asterisco na mesma linha não diferem pelo teste $\mathrm{SNK}(\mathrm{p}<0,05)$. CV = 43,99\% (produção parcial); $\mathrm{CV}=$ $28,76 \%$ (produção total)

novamente com destaque do genótipo ATF 53 $\mathrm{x}$ 912. Comparando-se os cortes, apenas para a cultivar BRS 800 foi observada estabilidade de produção com o decorrer dos cortes, sendo que, para as demais, foi observado um maior rendimento do segundo corte em relação aos outros dois.

Quanto às produções totais de MS, o genótipo ATF 53 x 912 apresentou valor médio semelhante ( $\mathrm{p}>0,05)$ ao da cultivar AG 2501-C, com média de $6,77 \mathrm{t} \mathrm{ha}^{-1}$ e superior $(\mathrm{p}<0,05)$ aos demais híbridos.

$\mathrm{Na}$ primeira época de semeadura, as produções totais de MS variaram entre 3,12 e 6,55 t.ha ${ }^{-1}$ e não houve diferença significativa ( $p>0,05)$ entre os híbridos. Entretanto, no terceiro corte, o genótipo ATF 53 x 912 apresentou produção semelhante à da cultivar AG 2501-C e superior aos demais híbridos.
Para forrageiras anuais em regime de corte, a persistência na produção ao longo dos cortes é uma característica desejável, por permitir utilizações sucessivas da cultura. No presente trabalho, quanto às produções de MS, para alguns híbridos, quando estas não foram constantes em relação ao primeiro corte, observou-se a tendência de aumento da produção, o que é mais interessante ainda, e demonstra, além da influência dos fatores ambientais, a capacidade de perfilhamento e crescimento dos híbridos de sorgo com capim-sudão. Comparando-se a produção média de MS na primeira época de semeadura, observou-se que esta foi inferior à produção média da segunda época.

$\mathrm{O}$ valor médio de MS na segunda época foi superior $(p>0,05)$ à média encontrada na primeira. Essas variações encontradas entre as épocas e os cortes foram devido, principalmente, 
às diferenças nos estádios/intervalos de colheita. Conforme já foi descrito, na primeira época, o primeiro corte foi realizado com 56 dias após a semeadura e os demais com 26 e 27 dias de rebrota, enquanto que, na segunda época, o primeiro corte foi realizado 48 dias após a semeadura e os demais com 32 e 41 dias de rebrota.

Segundo Jung et al. (1964), a produtividade de híbridos de sorgo com capimsudão é influenciada por diversos fatores, sendo o manejo de corte o mais importante. Tomich (2003) obteve produções médias de 3,2; 3,4 e 2,9 t MS.ha-1 para o primeiro, segundo e terceiro cortes, respectivamente, realizados no verão, para 12 híbridos de sorgo de corte e/ou pastejo.

Apesar de existirem diferenças entre as épocas de semeadura $(p<0,05)$, devido à não padronização dos períodos de corte, não seria prudente destacar uma época em relação à outra. As produções encontradas em ambas as épocas foram mais baixas do que os valores de 6,3 a 9,0 t.ha-1 encontrados por Ribas et al. (2002), para 12 híbridos de sorgo submetidos a três cortes e dos valores entre 6,8 e 11,6 t.ha-1 obtidos por Tomich (2003), no mesmo regime de cortes, mas trabalhando em outras épocas de semeadura. Diferentes condições experimentais, como o estádio de desenvolvimento das plantas (Worker Jr., 1973), a época de semeadura (Farias \& Winch, 1987) e a disponibilidade de água (Rodrigues, 2000) são capazes de influenciar a produção dos híbridos, dificultando dessa forma comparações entre pesquisas distintas.
A produção de MSD é um parâmetro de destaque na determinação do potencial forrageiro dos híbridos, visto que combina o valor nutritivo com a avaliação de produção. Os resultados obtidos para a produção de MSD, dos diferentes híbridos, estão na Tabela 3. Foi observada, para as produções de MSD, uma correlação de $0,99(\mathrm{p}<0,001)$ com a produção de MS, o que pode ser confirmado pelo padrão de resposta semelhante entre essas duas características.

Observando-se a média dos híbridos, para os genótipos 206 × 912 e 222 × 912, foram obtidos resultados médios nos diversos cortes de 0,72 e 0,82 t.ha ${ }^{-1}$, respectivamente, valores estes inferiores $(p<0,05)$ aos observados pelos híbridos ATF 53 x 912 e AG 2501-C.

$\mathrm{Na}$ primeira época, não foram obtidas diferenças entre os híbridos, para o primeiro e segundo cortes, com produções médias de 0,90 e 0,74 t.ha ${ }^{-1}$, respectivamente. No terceiro corte, como também observado para a produção de MS, o genótipo ATF 53 x 912 foi superior aos outros híbridos e semelhante apenas à testemunha $\mathrm{AG}$ 2501-C, que, por sua vez, foi similar à cultivar BRS 800 e ao genótipo 205 x 912 e superior aos demais.

Comparando-se os cortes na primeira época, para o híbrido ATF 53 x 912, foi encontrado o valor de 1,84 t.ha ${ }^{-1}$ de MSD no terceiro corte, produção esta superior aos valores obtidos nos cortes anteriores. Os demais híbridos mantiveram a produção durante a sucessão dos cortes. 


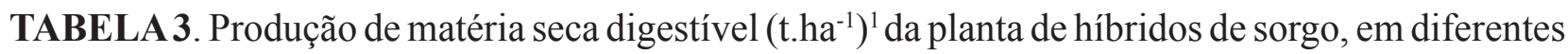
épocas de semeadura e corte.

\begin{tabular}{|c|c|c|c|c|c|c|c|c|c|}
\hline \multirow[b]{2}{*}{ Híbridos } & \multicolumn{4}{|c|}{$1^{\text {a Época }}$} & \multicolumn{4}{|c|}{$2^{\text {a Época }}$} & \multirow[b]{2}{*}{ Média } \\
\hline & $1^{\circ}$ Corte & $2^{\circ}$ Corte & $3^{\circ}$ Corte & $\begin{array}{c}\text { Produção } \\
\text { Total }\end{array}$ & $1^{\circ}$ Corte & $2^{\circ}$ Corte & $3^{\circ}$ Corte & $\begin{array}{c}\text { Produção } \\
\text { Total }\end{array}$ & \\
\hline $206 \times 912$ & $0,75 \mathrm{Aa}$ & $0,48 \mathrm{Aa}$ & $0,51 \mathrm{Ca}$ & 1,74 & $0,51 \mathrm{Ab}$ & 1,59 Ba' & $0,45 \mathrm{Cb}$ & 2,55 & $0,72 \mathrm{C}$ \\
\hline $205 \times 912$ & $0,88 \mathrm{Aa}$ & $0,75 \mathrm{Aa}$ & $0,77 \mathrm{BCa}$ & 2,40 & $0,56 \mathrm{Ab}$ & 1,92 $\mathrm{Ba}$ & $0,96 \mathrm{ABCb}$ & 3,44 & $0,97 \mathrm{BC}$ \\
\hline ATF53x912 & $1,01 \mathrm{Ab}$ & $0,75 \mathrm{Ab}$ & $1,84 \mathrm{Aa}$ & 3,6 & 0,88 Ac' & 2,71 Aa' & $1,64 \mathrm{Ab}$ & 5,23 & $1,47 \mathrm{~A}$ \\
\hline $222 \times 912$ & $0,75 \mathrm{Aa}$ & $0,70 \mathrm{Aa}$ & $0,56 \mathrm{Ca}$ & 2,01 & $0,62 \mathrm{Ab}$ & $1,56 \mathrm{Ba}^{\prime}$ & $0,70 \mathrm{BCb}$ & 2,88 & $0,82 \mathrm{C}$ \\
\hline AG 2501-C & $0,96 \mathrm{Aa}$ & $0,89 \mathrm{Aa}$ & $1,45 \mathrm{ABa}$ & 3,3 & $0,79 \mathrm{Ab}$ & $2,20 \mathrm{ABa}$ & $1,41 \mathrm{ABb}$ & 4,4 & $1,29 \mathrm{AB}$ \\
\hline BRS 800 & $1,02 \mathrm{Aa}$ & $0,87 \mathrm{Aa}$ & $1,06 \mathrm{BCa}$ & 2,95 & $0,82 \mathrm{Aa}^{\prime}$ & 1,44 Ba' & 1,09 ABCa' & 3,35 & $1,05 \mathrm{BC}$ \\
\hline Médias & 0,90 & 0,74 & 1,03 & 2,67 & 0,70 & 1,64 & 1,04 & 3,64 & \\
\hline Média das Épocas & & & $\mathrm{b}$ & & & & $1 \mathrm{a}$ & & \\
\hline
\end{tabular}

${ }^{1}$ Médias seguidas de letras maiúsculas iguais na mesma coluna, de letras minúsculas iguais na mesma linha e de letras minúsculas iguais com apóstrofe na mesma linha não diferem pelo teste $\mathrm{SNK}(\mathrm{p}<0,05) . \mathrm{CV}=43,40 \%$

Na segunda época, não foram observadas diferenças entre os híbridos no primeiro corte. Já no segundo corte, o genótipo ATF 53 x 912 apresentou rendimento semelhante ao da cultivar AG 2501-C e superior ao dos demais. No terceiro corte o genótipo ATF 53 x 912 apresentou rendimento superior ao dos genótipos $206 \mathrm{x}$ 912 e 222 x 912 e foi semelhante aos demais. A produção de MSD foi constante entre os cortes apenas para a cultivar BRS 800, sendo que, para os demais híbridos, foi notado maior rendimento no segundo corte em relação aos demais cortes. Isso pode ser devido principalmente à maior produção de MS, já que houve diminuição da digestibilidade.

A produção média de MSD na primeira época mostrou-se inferior à média apresentada na segunda época, com resultados de 0,89 e
1,21 t.ha $\mathrm{T}^{-1}$, respectivamente. O valor médio para a DIVMS foi próximo de 56\%, o que é capaz de permitir bons níveis produtivos aos animais alimentados com essas forrageiras. Neste experimento, pelas razões já explicadas, os intervalos de corte não foram constantes, o que dificulta uma recomendação da época mais adequada. Entretanto, os híbridos avaliados foram submetidos às mesmas condições de manejo durante a realização do experimento, destacando-se novamente o genótipo ATF 53 x 912. Na média dos híbridos, o genótipo ATF 53 x 912 apresentou resultado semelhante ao da cultivar AG 2501-C e superior ao dos demais, que foram semelhantes entre si.

Para os híbridos de sorgo de corte e/ou pastejo, a mensuração da altura das plantas é de grande importância para a determinação do 
momento ideal de corte ou pastejo, bem como do potencial de crescimento dos híbridos avaliados.

$\mathrm{Na}$ Tabela 4, encontram-se as médias de altura das plantas no momento de corte. O híbrido 206 x 912 apresentou altura média inferior aos demais, os quais foram semelhantes entre si $(\mathrm{p}>0,05)$.

Ao analisar a altura média das plantas em períodos diferentes, verifica-se que, na primeira época de semeadura, o genótipo 206 x 912 apresentou menor porte, em comparação ao AG 2501-C, no primeiro corte, e aos demais, no terceiro corte. Já na segunda época, o híbrido 206 x 912 também diferiu do AG 2501-C, mas apenas no terceiro corte. Todas os cultivares tiveram maior altura no segundo corte da segunda época de semeadura. Mas, na primeira época, apenas o híbrido ATF 33 x 912 diferiu entre os cortes, apresentando maior altura no terceiro período.
A importância da avaliação de altura de plantas para os híbridos de sorgo bicolor com o sorgo Sudão relaciona-se às suas correlações positivas com os parâmetros de produção e negativas com o valor nutritivo da forragem. Sendo assim, juntamente com a época, a altura pode ser um parâmetro para se determinar o momento de corte. No presente estudo, a altura das plantas foi positivamente $(p<0,001)$ correlacionada aos parâmetros de produção MV e MS, com valores de correlação igual a 0,78 e 0,79 , respectivamente. Deve-se destacar, neste experimento, as alturas médias de 123,4 cm observadas no segundo corte da segunda época, que foram obtidas com 32 dias de rebrota, demonstrando a grande capacidade de crescimento dos híbridos de sorgo para corte e/ ou pastejo.

A obtenção do número de plantas no momento do corte de híbridos de sorgo de corte

TABELA 4. Altura da planta $(\mathrm{cm})^{1}$ de híbridos de sorgo, em diferentes épocas de semeadura e corte.

\begin{tabular}{|c|c|c|c|c|c|c|c|}
\hline \multirow{2}{*}{ Híbridos } & \multicolumn{3}{|c|}{$1^{a}$ Época } & \multicolumn{3}{|c|}{$2^{a}$ Época } & \multirow[t]{2}{*}{ Média } \\
\hline & $1^{\circ}$ Corte & $2^{\circ}$ Corte & $3^{\circ}$ Corte & $1^{\circ}$ Corte & $2^{\circ}$ Corte & $3^{\circ}$ Corte & \\
\hline $206 \times 912$ & $70,0 \mathrm{Ba}$ & $43,7 \mathrm{Aa}$ & $58,7 \mathrm{Ba}$ & $62,5 \mathrm{Ab}$ & $103,7 \mathrm{Aa}$ & $50,0 \mathrm{Bb}$ & $64,8 \mathrm{~B}$ \\
\hline $205 \times 912$ & $100,0 \mathrm{Aa}$ & $53,7 \mathrm{Ab}$ & $81,2 \mathrm{Aa}$ & $78,7 \mathrm{Ab}$ & $135,0 \mathrm{Aa}$ & 93,7 Ab' & $90,4 \mathrm{~A}$ \\
\hline ATF $53 \times 912$ & $103,7 \mathrm{Aa}$ & $50,0 \mathrm{Ab}$ & $108,7 \mathrm{Aa}$ & $83,7 \mathrm{Ab}$ & $135,0 \mathrm{Aa}$ & $92,5 \mathrm{Ab}$ & $95,6 \mathrm{~A}$ \\
\hline $222 \times 912$ & $85,0 \mathrm{ABa}$ & $55,0 \mathrm{Ab}$ & $98,7 \mathrm{Aa}$ & $82,5 \mathrm{Ab}$ & $127,5 \mathrm{Aa}^{\prime}$ & 73,7 ABb' & $87,1 \mathrm{~A}$ \\
\hline AG 2501-C & $106,2 \mathrm{Aa}$ & $45,0 \mathrm{Ab}$ & $87,5 \mathrm{Aa}$ & $88,7 \mathrm{Ab}$ & $127,5 \mathrm{Aa}$ & $85,0 \mathrm{Ab}$ & $90,0 \mathrm{~A}$ \\
\hline BRS 800 & $82,5 \mathrm{ABab}$ & $61,2 \mathrm{Ab}$ & $98,7 \mathrm{Aa}$ & $68,7 \mathrm{Ab}$ & $112,5 \mathrm{Aa}^{\prime}$ & $76,2 \mathrm{ABb}$ & $83,3 \mathrm{~A}$ \\
\hline Médias & 91,2 & 51,5 & 89,0 & 77,5 & 123,4 & 78,5 & \\
\hline Médias das Épocas & & $77,2 \mathrm{~b}$ & & & $93,2 \mathrm{a}$ & & \\
\hline
\end{tabular}

${ }^{1}$ Médias seguidas de letras maiúsculas iguais na mesma coluna, de letras minúsculas iguais na mesma linha e de letras minúsculas iguais com apóstrofe na mesma linha não diferem pelo teste $\mathrm{SNK}(\mathrm{p}<0,05)$. CV $=18,81 \%$ 
e/ou pastejo é importante para a avaliação do potencial produtivo. O número de plantas por hectare deste experimento, no momento do corte, está representado na Tabela 5. Observando-se a média dos híbridos, verifica-se que as cultivares AG 2501-C, BRS 800 e o genótipo experimental ATF 53 x 912 apresentaram médias semelhantes e foram superiores $(p<0,05)$ aos outros três genótipos do experimento.

Comparando-se os cortes na primeira época de semeadura, com exceção do genótipo 206 x 912, que já diminuiu a população a partir do segundo corte, todos os outros híbridos apresentaram queda da população de plantas por ocasião do terceiro corte. $\mathrm{Na}$ segunda época, os híbridos AG 2501-C, BRS 800 e 206 x 912 diminuíram a população de plantas a partir do segundo corte, enquanto que, para os outros três híbridos, esse fato ocorreu no terceiro corte.
O número médio de plantas por ocasião da colheita, para a primeira época de semeadura, foi superior $(p<0,05)$ ao da segunda época.

Diferenças significativas na população de plantas no primeiro corte, entre híbridos, podem indicar uma maior capacidade de germinação das sementes e estabelecimento cultural para alguns deles nas condições experimentais.

Alguns trabalhos (Worker Jr., 1973; Medeiros et al., 1979) relacionam a produtividade de híbridos de sorgo bicolor com capim-sudão ao aumento da população de plantas. No presente trabalho, não foram observadas correlações desse parâmetro com os parâmetros de produção de MV e MS, o que pode ser devido ao grande número de plantas observado, principalmente durante o primeiro corte das duas épocas. Tomich (2003) encontrou valores médios de 653,4 mil plantas por hectare no momento do primeiro corte, enquanto que Ribas et al. (2002)

TABELA 5. População de plantas (1.000 plantas.ha-1 $)^{1}$ de híbridos de sorgo, em diferentes épocas de semeadura e corte.

\begin{tabular}{|c|c|c|c|c|c|c|c|}
\hline \multirow{2}{*}{ Híbridos } & \multicolumn{3}{|c|}{$1^{\mathrm{a}}$ Época } & \multicolumn{3}{|c|}{$2^{\mathrm{a}}$ Época } & \multirow{2}{*}{ Média } \\
\hline & $1^{\circ}$ Corte & $2^{\circ}$ Corte & $3^{\circ}$ Corte & $1^{\circ}$ Corte & $2^{\circ}$ Corte & $3^{\circ}$ Corte & \\
\hline $206 \times 912$ & $1054 \mathrm{Aa}$ & $660 \mathrm{Cb}$ & $407 \mathrm{Bc}$ & 795 Aba' & $474 \mathrm{Bb}$ & $462 \mathrm{Ab}$ & $641 \mathrm{~B}$ \\
\hline $205 \times 912$ & 929 Аа & $827 \mathrm{BCa}$ & $388 \mathrm{Bb}$ & $615 \mathrm{Ba}^{\prime}$ & 619 Aba' & $328 \mathrm{Ab}$ & $618 \mathrm{~B}$ \\
\hline ATF53x912 & $1174 \mathrm{Aa}$ & $971 \mathrm{ABa}$ & $688 \mathrm{Ab}$ & 987 Аa’ & 869 Аа' & $458 \mathrm{Ab}$ & $858 \mathrm{~A}$ \\
\hline $222 \times 912$ & $955 \mathrm{Aa}$ & $775 \mathrm{BCa}$ & $344 \mathrm{Bb}$ & 754 Aba' & 550 Aba' & $305 \mathrm{Ab}$ & $614 \mathrm{~B}$ \\
\hline AG 2501-C & $958 \mathrm{Aa}$ & $1116 \mathrm{Aa}$ & $711 \mathrm{Ab}$ & 899 Aba' & $588 \mathrm{Abb}$ & $406 \mathrm{Ab}$ & $780 \mathrm{~A}$ \\
\hline BRS 800 & $1055 \mathrm{Aa}$ & $998 \mathrm{ABa}$ & $629 \mathrm{ABb}$ & $836 \mathrm{Aba}$ & $576 \mathrm{Abb}$ & $396 \mathrm{Ab}$ & $748 \mathrm{~A}$ \\
\hline Médias & 1021 & 891 & 528 & 814 & 613 & 388 & 607 \\
\hline Média das Épocas & & 813 a & & & $607 \mathrm{~b}$ & & \\
\hline
\end{tabular}

${ }^{1}$ Médias seguidas de letras maiúsculas iguais na mesma coluna, de letras minúsculas iguais na mesma linha e de letras minúsculas iguais com apóstrofe na mesma linha não diferem pelo teste SNK $(\mathrm{p}<0,05)$. CV $=23,06 \%$ 
encontraram 375,65 mil plantas.ha-1 ${ }^{-1}$ Esses valores são bem menores que os valores médios de 1021,37 e 814,75 mil plantas.ha ${ }^{-1}$ obtidos no primeiro corte da primeira e segunda época, respectivamente, no presente trabalho.

Como normalmente o número e a massa das plantas determinam a produtividade da forragem, a interação entre estes dois fatores, juntamente com altura, proporcionaram a maior produtividade de alguns cortes, mesmo com a menor população de plantas.

As produções totais de $\mathrm{MS} \mathrm{ha}^{-1}$ obtidas neste experimento podem ser consideradas satisfatórias, levando-se em conta a época de semeadura. Indicam que os híbridos de sorgo para corte e/ou pastejo podem ser uma excelente opção para produção de forragem cultivada no período inicial de safra das pastagens, de forma a diminuir as necessidades de suplementação nesse período, bem como, ao reduzir a carga animal, auxiliar na recuperação das pastagens.

\section{Conclusões}

O híbrido ATF 53 x CMSXS 912 apresentou valores médios de produção de MV e MS e MSD superiores nas duas épocas de semeadura, sem diferir da testemunha AG 2501C.

Os valores médios da $2^{\mathrm{a}}$ época de semeadura foram superiores aos da $1^{\mathrm{a}}$ época quanto às produções totais de $\mathrm{MV}, \mathrm{MS} \mathrm{e}$ altura das plantas, indicando maior capacidade produtiva na $2^{\mathrm{a}}$ época de semeadura.
Nas duas épocas de semeadura, os híbridos de sorgo com capim-sudão mantiveram a capacidade produtiva de forragem até o terceiro corte.

\section{Literatura Citada}

BORGES, A. L. C. C.; RABELO, L. S.; GONTIJO,M.R.;PENNA,A.G.; GONÇALVES, L .C.; BORGES, I.; RODRIGUES, J .A. S.; FERREIRA， J. J.; RODRIGUES， N. M.; SOBREIRA, R. F.; SALIBA, E. O. S.; LIMA, J. B. M. P.; PATRIZI, W. L. Produção de matéria verde, matéria seca e matéria seca digestível de híbridos de "Sorghum Bicolor" com "Sorghum Sudanense". In: REUNIÃO DA SOCIEDADE BRASILEIRA DE ZOOTECNIA, 40., 2003, Santa Maria. Anais... Santa Maria: SBZ, 2003. CD-ROOM.

CUNNIFF, P. (Ed.). Official methods of analysis of AOAC international. 16.ed. Washington: AOAC, 1995. 2000 p.

EUCLIDES, V. P. B. Manejo de pastagens para bovinos de corte. In: CURSO DE PASTAGENS - etapa 2, 2002, Campo Grande. Programa Repasto-Seprod. Campo Grande: Repastro/ Embrapa Gado de Corte, 2002. p. 1-21.

FARIAS, J. M.; WINCH, J. E. Effect of planting date and harvest stage upon yield, yield distribution and quality of Sorghum sudangrass in northern Mexico. Journal of Tropical Agriculture, St. Augustine, v. 64, n. 2, p. 87-90, 1987.

JUNG, G. A.; LILLY, B.; SHIH, S. C.; REID, R. L. Studies with sudangrass. I. Effect of growth

Revista Brasileira de Milho e Sorgo, v.9, n.1, p. 93-105, 2010

Versão impressa ISSN 1676-689X / Versão on line ISSN 1980-6477 - http://www.abms.org.br 
stage and level of nitrogen fertilizer upon yield of dry matter; estimated digestibility of energy, dry matter, and protein; amino acid composition; and prussic acid potential. Agronomy Journal, Madison, v. 56, p. 533-537, 1964.

MEDEIROS, R. B.; SAIBRO, J. C.; BARRETO, I. L. Efeito do nitrogênio e da população de plantas no rendimento e qualidade do sorgo Sordan (Sorghum bicolor (L.) Moench) x (Sorghum sudanense (Piper) Stapf). Revista Brasileira de Zootecnia, Viçosa, MG, v. 8, n.1, p.75-87, 1979.

RAUPP, A. A. A.; BRANCÃO, N.; FRANCO, J. C. B. Ensaio Sul Riograndense de sorgo forrageiro para corte e pastejo 1998/99. Capão do Leão, RS. In: REUNIÃO TÉCNICAANUAL DO MILHO, 44.; REUNIÃO TÉCNICA DO SORGO, 27., 1999, Porto Alegre. Anais... Porto Alegre: FEPAGRO: EMATER-RS: FECOAGRO, 1999. p.131-133.

RIBAS, M. N.; TOMICH, T. R.; GLÓRIA, I. R.; GONÇALVES, L.C.; RIBEIRO, C. G. M.; RODRIGUES, J. A. S. Produção de matéria seca e de matéria natural, teor de matéria seca, altura de planta e relação folha/colmo de doze híbridos de sorgo submetidos a três cortes. In: REUNIÃO DA SOCIEDADE BRASILEIRA DE ZOOTECNIA. 39., 2002, Recife, PE. Anais... Recife: SBZ, 2002. CD-ROOM.

RODRIGUES, J. A. S. Utilização de forragem fresca de sorgo (Sorghum bicolor x Sorghum sudanense) sob condições de corte e pastejo. In: SIMPÓSIO DE FORRAGICULTURA E PASTAGENS, 2000., Lavras. Temas em evidência... Lavras: UFLA, 2000. p.179-201.
TILLEY, J. M. A.; TERRY, R. A. A two-stage technique for the "in vitro" digestion of forage crops. Journal of the British Grassland Society, Oxford, v. 18, n. 2, p.104-111, 1963.

TOMICH, T. R.; RODRIGUES, J. A. S.; GONÇALVES, L. C. PINTO, R. G.; BORGES, I.; RODRIGUES, N. M. Produção e proporções de folha e de colmo de doze híbridos de sorgo em manejo de corte, avaliados na rebrota. In: REUNIÃO DA SOCIEDADE BRASILEIRA DE ZOOTECNIA, 38., 2001, Piracicaba. Anais... Piracicaba: SBZ, 2001. p.291-292.

TOMICH, T. R. Potencial forrageiro de híbridos de sorgo com capim Sudão (Sorghum bicolor $x$ Sorghum sudanense) avaliados em regime de corte. 2003. 88 f. Tese (Doutorado) Escola de Veterinária, Universidade Federal de Minas Gerais, Belo Horizonte.

UNIVERSIDADE FEDERAL DE VIÇOSA. SAEG - Sistema de análises estatísticas e genéticas (manual do usuário). Versão 8.0. Viçosa, MG, 2000. 142 p.

WORKER JR., G. F. Sudangrass and sudangrass hybrids responses to row spacing and plant maturity on yield and chemical composition. Agronomy Journal, Madison, v. 65, n. 6, p. 975-977, 1973.

ZAGO, C. P. Utilização do sorgo na alimentação de ruminantes. In: MANEJO cultural do sorgo para forragem. 2. ed. Sete Lagoas: Embrapa Milho e Sorgo, 1997. p. 9-26. (Embrapa Milho e Sorgo. Circular Técnica, 17) 
